\title{
A atividade de "Indicação de leitura" realizada no IFSP: promoção de práticas de incentivo à leitura
}

\author{
The activity of "Reading Assignment" held at the IFSP: promoting practices to encourage \\ reading
}

\begin{abstract}
Cintia Almeida da Silva Santos
Mestre em Ciência, Tecnologia e Sociedade pela Universidade Federal de São Carlos - UFSCar. Bibliotecária do Instituto Federal de Educação, Ciência e Tecnologia de São Paulo, campus Araraquara.

E-mail: cintiasert@hotmail.com
\end{abstract}

Marcel Pereira Santos

Mestrando em Ciência, Tecnologia e Sociedade pela Universidade Federal de São Carlos - UFSCar. Bibliotecário do Instituto Federal de Educação, Ciência e Tecnologia de São Paulo, campus Araraquara

E-mail: mpsantos_2004@yahoo.com.br

\section{Resumo}

A promoção de práticas de incentivo à leitura é frequentemente realizada pelos bibliotecários e demais profissionais da informação na tentativa de apresentar aos usuários das bibliotecas e demais unidades de informação a leitura como um evento social, prazeroso e não obrigatório, que pode permear diversas vertentes do mundo real ao mundo imaginário. $\mathrm{O}$ ato da leitura nada custa ao leitor ao mesmo tempo em que o enriquece e $\mathrm{o}$ engrandece à medida que propicia a construção de novos conhecimentos. Este artigo abarca a importância da realização das práticas de incentivo à leitura na contribuição da formação do aluno leitor e também apresenta o relato de uma simples experiência pensada, organizada e realizada pela Biblioteca do Instituto Federal de Educação, Ciência e Tecnologia de São Paulo - Campus Araraquara chamada "Indicação de Leitura" esta atividade objetiva apresentar aos usuários da biblioteca o fantástico mundo literário ali disponível. A atividade que é realizada mensalmente gerou um aumento significativo no empréstimo das obras literárias indicadas para leitura, fator que demonstrou a participação e o envolvimento dos usuários da biblioteca com esta atividade.

Palavras-chave: Biblioteca Escolar. Práticas de Incentivo à Leitura. Instituto Federal de São Paulo.

\begin{abstract}
Promoting practices to encourage reading is often performed by librarians and other information professionals in an attempt to present users of libraries and other information units reading as a social event, pleasurable and not required, that can permeate various aspects of the world real to the imaginary world. The act of reading nothing costs the player while that enriches and enlarges the extent that promotes the construction of new knowledge. This article covers the importance of holding practices to encourage reading in the contribution of student education reader and also presents an account of a simple thought experiment, organized and held by the Library of the Federal Institute of Education, Science and Technology of São Paulo - Campus Araraquara called "Indication Reading" this activity aims to provide library users the amazing literary world there available. The activity that is conducted monthly generated a significant increase in the loan given to the literary reading, a factor that demonstrated the participation and involvement of the users of the library with this activity.
\end{abstract}

Keywords: School Library. Practice Reading Incentive. Federal Institute of São Paulo. 


\section{Introdução}

A promoção de atividades de incentivo à leitura é amplamente difundida por bibliotecários, jornalistas, escritores, dentre outros profissionais e também cidadãos que enxergam e leitura como um evento social e cultural capaz de fornecer ao leitor a possibilidade de novos conhecimentos, novas experiências e novas transformações a partir da leitura. Verifica-se tais feitos nos diversos artigos, relatos de experiência e eventos biblioteconômicos no âmbito da Ciência da Informação ${ }^{1}$. Para promover e incentivar à leitura cada profissional trabalha à sua maneira e com os recursos que dispõe em seu ambiente de trabalho, sendo estes recursos particulares, privados, públicos, entre outros, com o objetivo de apresentar aos seus potenciais leitores os múltiplos universos que a leitura possibilita. A prática da promoção de atividades de incentivo à leitura é comumente realizada por bibliotecários em seus ambientes de trabalho. De acordo com Silveira o ato da leitura pode ser compreendido como um "trabalho do pensamento, em recurso de apropriação do mundo, em movimento de ressignificação da realidade" (SILVEIRA, 2012, p.146), ou seja, a leitura é ato introspectivo que atribui ao leitor diferentes possibilidades de interpretações, sentidos e valores, ainda conforme Silveira:

a leitura de qualquer texto é, portanto, um processo de construção cultural e histórica, que se efetiva a partir da mescla entre as condições materiais destinadas à sua produção e circulação, com a subjetividade e o lugar em que cada leitor se encontra no momento de executá-la (SILVEIRA, 2012, p. 146).

Desta forma, compreende-se que a biblioteca pode ser um organismo provedor e incentivador deste "trabalho do pensamento", pois ela pode fomentar a promoção de atividades de incentivo à leitura, tendo no bibliotecário, a figura de intermediador, como também sinaliza Silveira (2012). Portanto, a promoção de atividades de incentivo à leitura é uma tarefa que deverá ser contínua e cada vez mais desenvolvida, tendo em vista que o Brasil apresenta um modesto índice de práticas de leitura. De acordo com a pesquisa Retratos da Leitura no Brasil ${ }^{2}$, realizada pelo Instituto Pró-Livro (IPL), que teve em 2011 a sua terceira aplicação, está sendo construído um panorama nacional dos hábitos de leitura dos brasileiros, tais informações estão sintetizadas e interpretadas satisfatoriamente no livro Retratos da Leitura no Brasil 3, organizado por Failla:

\footnotetext{
${ }^{1}$ Estas observações poderão ser verificadas no site oficial do Programa Nacional de Incentivo à Leitura (PROLER): http://www.bn.br/proler.

${ }^{2}$ Retratos da Leitura no Brasil é uma pesquisa pioneira e completa em âmbito nacional que aborda os hábitos de leitura dos brasileiros, é realizada pelo Instituto Pró-Livro. Maiores informações sobre a pesquisa poderão ser encontradas através do site: http://www.prolivro.org.br/ipl/publier4.0/texto.asp?id=2834.
} 
Com relação aos resultados da última pesquisa, dada a conhecer em 2012, causou estranheza e incômodo o fato de que seus dados apontavam para a diminuição do índice de leitura entre os brasileiros: se, em 2007, 55\% dos brasileiros entrevistados se classificavam como leitores, em 2011 eles não passaram de 50\%. Para a média de livros lidos no ano, observou-se igualmente um declínio: de 2,7 livros (excetuados os didáticos), para 1,85 (FAILLA, 2012, p. 84).

A pesquisa Retratos da Leitura no Brasil aborda com profundidade o perfil dos leitores brasileiros e apresenta indicadores que possibilitam subsidiar projetos e programas de incentivo à leitura. Desta forma, pesquisar e discursar sobre práticas de incentivo e de estímulo à leitura se faz cada vez mais necessário, haja vista o longo caminho a percorrer pela institucionalização e democratização da leitura no país. Este artigo abarca a importância da realização das práticas de incentivo à leitura na contribuição da formação do aluno leitor e também apresenta o relato de uma simples experiência pensada, organizada e realizada pela Biblioteca do Instituto Federal de Educação, Ciência e Tecnologia de São Paulo - Campus Araraquara chamada "Indicação de Leitura".

\section{A importância da leitura para o desenvolvimento do leitor}

Abarcam-se neste artigo aspectos relativos à leitura não obrigatória, ou seja, a descrição e a análise da leitura no contexto deste artigo são feitas sobre a leitura espontânea e não forçada. A leitura apresenta para o leitor possibilidades de enxergar "além dos muros", na medida em que exige deste leitor: concentração, introspecção, imaginação e interpretação. Neste sentido o contexto é propício para explicitar uma famosa frase do escritor Vargas Llosa $^{3}$, "um público comprometido com a leitura é crítico, rebelde, inquieto, pouco manipulável e não crê em lemas que alguns fazem passar por ideias", ou seja, o ato de ler pode libertar, inquietar e instigar as pessoas para novas descobertas, comprovação e negação, é certo que não se pode atribuir à leitura a responsabilidade de resolver os todos os problemas da humanidade, ou nomear que o sujeito leitor é melhor do que o sujeito não leitor e sim é válido ressaltar que o sujeito leitor possui o contato com obras em que ele adquiri a autonomia para ler, repelir e até indicar para que outros sujeitos a leiam como apontam as autoras Bertaglia e Trevizan (2012), portanto, a leitura é passível de contemplar o sujeito leitor de criatividade, sensibilidade e crítica, como apontam as autoras supracitadas (BERTAGLIA; TREVIZAN, 2012), para as autoras “o leitor refina suas percepções e passa a ver um mundo

\footnotetext{
3 Jorge Mario Pedro Vargas Llosa, nascido em 28 de março de 1936 em Arequipa no Perú é um escritor, jornalista e também político, foi laureado com o Prêmio Nobel de Literatura no ano de 2010. Site oficial: www.mvargasllosa.com
}

Bibl. Esc. em Rev., Ribeirão Preto, v. 2, n. 1, p. 55-68, 2013. 
sob outra ótica. Além disso, será capaz de recorrer às suas lembranças e experiências literárias em diversos e diferentes momentos de sua existência, atribuindo à leitura um sentido de força vital" (BERTAGLIA; TREVIZAN, 2012).

Os autores Frasson, Pricinotto e Fecchio relatam que a leitura pode trazer aos leitores situações novas e que podem esclarecer pontos duvidosos, podem ainda atiçar as curiosidades dos leitores para mundos desconhecidos, cada leitor, no momento da leitura possui um objetivo singular, desta forma a leitura é feita mediante um propósito do leitor e se este propósito estiver aliado ao prazer, a não obrigação e a liberdade, os frutos da leitura serão nutritivos e salutares (FRASSON; PRICINOTTO; FECCHIO, 2004, p. 128), de forma a abrirem portas para reflexões e pensamentos sob novos pontos de vista. Desta forma a leitura possui papel fundamental no desenvolvimento do senso crítico do leitor, reflete-se que antes de tudo o leitor é um cidadão que pode a partir de novas possibilidades, pensar diferente e por conseguinte agir também de forma diferenciada.

\section{As bibliotecas do Instituto Federal de Educação, Ciência e Tecnologia de São Paulo}

As bibliotecas dos Institutos Federais de Educação, Ciência e Tecnologia possuem uma tipologia diferenciada das tradicionais bibliotecas, tendo em vista que são organismos integrantes de instituições também diferenciadas, pois os Institutos Federais de Educação, Ciência e Tecnologia, popularmente conhecidos como Institutos Federais são autarquias federais que carregam em sua concepção uma estrutura pluricurricular, multicampi que devem equalizar uma porcentagem para oferecimento das variadas modalidades de ensino: $50 \%$ para cursos técnicos; $30 \%$ para cursos superiores em tecnologia; $20 \%$ para cursos de licenciaturas (BRASIL, 2008), ou seja, os Institutos Federais podem oferecer diferentes modalidades de ensino, que podem variar desde o ensino médio integrado ao curso técnico a cursos de pósgraduação. Ressalta-se que os Institutos Federais são as centenárias e tradicionais Escolas de Aprendizes e Artífices fundadas em 1909, que passaram por várias transformações (IFSP, 2013). Desta forma, as bibliotecas dos Institutos Federais congregam em um mesmo ambiente diferentes perfis de usuários, consequentemente diferentes necessidades informacionais.

O Instituto Federal de Educação, Ciência e Tecnologia de São Paulo, mais conhecido como Instituto Federal de São Paulo (IFSP) possui atualmente vinte e cinco campi e dez polos de Educação à Distância no estado de São Paulo, possui aproximadamente vinte e dois mil 
alunos matriculados (IFSP CAMPUS ARARAQUARA, 2013). Cada campus possui em sua estrutura organizacional uma biblioteca. Santos define as bibliotecas do IFSP como:

\begin{abstract}
sistemas informativos inseridos em sistemas maiores. No caso de cada biblioteca específica, o campus representa este sistema maior. Estas bibliotecas deverão prestar assessoria aos processos de ensino-aprendizagem, aos processos investigativos, aos processos extensionistas e especializados de cada campus, dotando-se de infraestrutura informacional para estes fins e assim atenderem as demandas de seus respectivos campi (SANTOS, 2012, p. 80).
\end{abstract}

A autora relata que as bibliotecas do IFSP congregam aspectos tipológicos das bibliotecas universitárias, escolares e especializadas, tendo em vista o caráter singular dos Institutos Federais (SANTOS, 2012, p. 80).

O campus Araraquara possui pouco mais de dois anos de existência, iniciou suas atividades no ano de 2010. Atualmente oferta os cursos:

- Técnicos Integrados ao Ensino Médio em Informática e Mecânica;

- Técnicos concomitantes (o aluno já cursou ou cursa o Ensino Médio em outra instituição) em Informática e Mecatrônica;

- Cursos Superiores em Tecnologia em Análise e Desenvolvimento de Sistemas e Mecatrônica Indústria;

- Licenciatura em Matemática.

A biblioteca do IFSP Campus Araraquara iniciou suas atividades no segundo semestre de 2011, possui um acervo ainda pequeno, com foco nas áreas de Informática, Matemática, Mecânica e Mecatrônica. Seu acervo é composto por livros e revistas, atualmente existe apenas uma servidora lotada na biblioteca que é bibliotecária, responsável pelos procedimentos administrativos e técnicos da biblioteca do campus.

O campus Araraquara possui $384^{4}$ alunos matriculados nos cursos anteriormente citados, vivencia um processo de expansão estrutural, arquitetônica e também no quadro dos servidores para que seja possível ampliar a oferta de vagas para o município de Araraquara e região (IFSP CAMPUS ARARAQUARA, 2013).

Apresentou-se sumariamente um breve retrato do IFSP Campus Araraquara e de sua biblioteca para que na seção seguinte seja descrita uma das atividades de promoção à leitura realizada pela biblioteca.

\footnotetext{
${ }^{4}$ Quantitativo obtido através de solicitação da bibliotecária via correio eletrônico à Coordenadoria de Registros Escolares do IFSP Campus Araraquara.
}

Bibl. Esc. em Rev., Ribeirão Preto, v. 2, n. 1, p. 55-68, 2013. 
Recorre-se aos autores Burke (2003) e Silveira (2012) para destacar a importância da biblioteca como um organismo fomentador de práticas de leitura, de buscas e trocas informacionais.

\title{
Segundo Silveira:
}

\begin{abstract}
Ao lançar seu olhar sobre a história da leitura, um observador atento percebe de imediato que a biblioteca se configura, de fato, como lócus privilegiado para que a alquimia da leitura se desenvolva e se efetive, por entre seus corredores e estantes que se preservam a infinitude do conhecimento humano, cada usuário se sente confortável para buscar, encontrar e utilizar determinada informação, convertendo-a posteriormente em insumo gerador de novos conhecimentos (SILVEIRA, 2012, p. 149-150).
\end{abstract}

As bibliotecas em suas diferentes tipologias podem atuar como organismos provedores e incentivadores das práticas de leitura, fomentando cada vez mais e continuamente atividades de incentivo à leitura, tendo no bibliotecário, a figura de intermediador deste processo. Conforme Silveira as bibliotecas podem ser consideradas locais armazenadores de muitas histórias que despertam nos leitores o fascínio e o encantamento, estes elementos se transmutam, perturbam e excitam as fantasias destes leitores, fazendo com que o sonhe se imbrique com a ação, o que promove medo e instiga reações (SILVEIRA, 2012, p.152), ou seja, a biblioteca possui grande relevância na vida do leitor, à medida que contribui para o seu despertar literário. Para os autores Copolla Júnior e Castro Filho, que são pesquisadores atuantes na temática das Bibliotecas Escolares "assim como o professor é o personagem central da escola, o bibliotecário também é na biblioteca escolar. Ambos profissionais podem contribuir para alcançar um avanço educacional" (COPOLLA JÚNIOR; CASTRO FILHO, 2012, p. 31), ou seja, a biblioteca pode ser um organismo fundamental para o aprimoramento educacional, social e cultural do leitor.

\subsection{A atividade de "Indicação de Leitura" realizada na biblioteca do IFSP Campus Araraquara}

A identidade da biblioteca do IFSP Campus Araraquara está em construção, desta forma, pretende-se que esta identidade seja envolta por um ambiente agradável que ofereça e possibilite a obtenção de diversos tipos de informações: informação técnica obrigatória para a completude dos cursos destes usuários; a informação de utilidade pública; a informação literária; a informação biografia, a informação artística e cultural em seus variados gêneros (música, pintura, dança, dentre outros) e que possua como objetivo principal a fidelização de seus usuários, oferecendo a eles um atendimento o encaminhamento das necessidades 
informacionais destes usuários, pois como mencionado por Santos e Santos "o pensamento de toda e qualquer biblioteca deverá ser o de prover aos seus usuários o acesso à informação" (SANTOS, SANTOS, 2012, p. 15).

A Biblioteca do IFSP Campus Araraquara desenvolve atualmente algumas atividades que sisa a promoção de incentivo à leitura, dentre eles descreve-se neste artigo uma das atividades realizada na biblioteca, esta atividade é realizada mensalmente denominada "Indicação de Leitura", a cada mês uma obra literária que compõe o acervo da biblioteca é indicada para ser divulgada durante aquele mês. A indicação pode ser feita pelos discentes, docentes ou técnico-administrativos do IFSP Campus Araraquara e deverão ser indicadas somente obras literárias que se encontram disponíveis para empréstimo no acervo da biblioteca, de maneira que os usuários possuam condições de efetuarem o empréstimo da obra. A biblioteca organiza um cartaz com informativos sobre a obra indicada e efetua a divulgação, que é feita por e-mail aos servidores do campus, cartazes são afixados nos murais do campus e também é feita a divulgação no site institucional do campus.

A Atividade teve início em março de 2012, começou de maneira tímida, já que no período o acervo literário da biblioteca era composto por poucos títulos que em sua maioria foram doados por um docente do campus, que também é escritor, sendo este um nato incentivador e divulgador literário.

No começo da atividade a bibliotecária instigava os leitores para que lessem as poucas obras literárias contidas no acervo, quando conseguia tal feito, a bibliotecária posteriormente solicitava para o usuário que leu a obra, que este a permissão para a indicação e a divulgação da obra, assim era atribuída aquele usuário leitor a indicação daquela obra literária que era divulgada no mês subsequente ao da leitura. E assim a atividade continua sendo realizada mensalmente e com o crescimento do acervo literário na biblioteca do campus os usuários possuem cada dia mais opções de leitura e de interação e fidelização com a sua biblioteca.

\section{Metodologia}

Foi realizado um levantamento bibliográfico sobre as temáticas: biblioteca escolar; práticas de incentivo à leitura e formação do leitor para embasamento dos pressupostos teóricos que este artigo abriga, foi escolhida e utilizada a técnica de coleta de dados questionário para a obtenção dos dados necessários, o questionário foi instrumento 
fundamental para mapear o perfil do usuário e identificar a percepção destes usuários perante as indicações de leitura. Especificamente utilizou-se em algumas questões as escalas de Likert para medir a percepção (gráficos 4, 5, 6 e 7), segundo Brandalise et al. (2009), Rensis Likert elaborou em 1932 uma escala para medir níveis de satisfação, chamadas de escalas de Likert, ou escalas Somadas, cujo método é requerer que os entrevistados indiquem seu grau de concordância ou discordância com afirmações relativas à situação analisada. Atribui-se valores numéricos às respostas para refletir a força e a direção da reação do entrevistado relativo à afirmação do questionário. A escala utilizada neste estudo foi de 0 a 10 , portanto, cada pergunta possuía cinco alternativas cujos valores atribuídos foram: $0 ; 2.5 ; 5 ; 7.5 ; 10$. Após elaboração do questionário utilizou-se a ferramenta gratuita Google Docs para armazenamento das respostas dos entrevistados, o questionário foi disponibilizado de modo on-line por um período de 15 dias, cada usuário da biblioteca foi convidado a responder o questionário por e-mail, foi explicitado que o mesmo não teria a obrigação de participar, porém, a participação contribuiria com a pesquisa desenvolvida e também com a melhoria dos serviços prestados pela biblioteca. O questionário foi enviado no mês de janeiro de 2013 para 343 usuários (docentes, discentes e técnico-administrativos), obteve-se 54 respostas, que representa $15 \%$ do total de usuários da biblioteca.

A análise dos dados obtidos com a coleta de dados foi realizada no mês de fevereiro de 2013.

O levantamento bibliográfico respaldou os conceitos previamente definidos de que a promoção de práticas de incentivo à leitura em diversos ambientes, especificamente nas bibliotecas se faz necessária, a figura do um bibliotecário atuante como mediador informacional e uma biblioteca estruturada e interessada na fidelização de seus usuários são fatores relevantes para o desenvolvimento e consolidação de projetos e programas de incentivo à leitura.

\section{Resultados e Discussão}

Com base na massa documental oriunda dos 54 questionários respondidos apresentamse os gráficos elaborados e uma breve análise de cada questão. 
Gráfico 1 - Qual o curso (para alunos) e qual o segmento (para servidores)

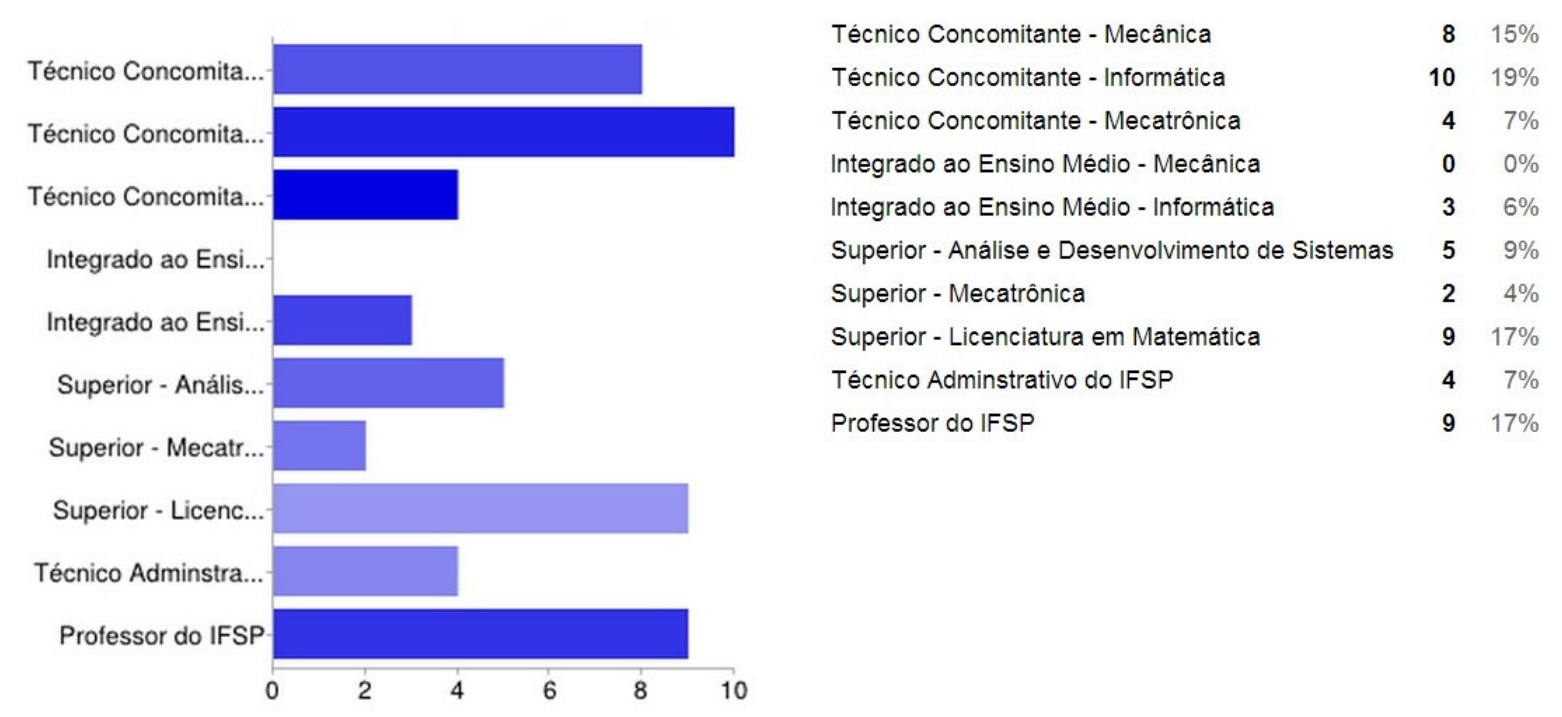

Com relação primeira questão identificou-se uma participação expressiva dos docentes e dos discentes dos cursos técnicos concomitantes ${ }^{5}$ em Informática, Mecânica e Mecatrônica. Salienta-se que houve participação dos três segmentos do IFSP Campus Araraquara (docentes, discentes e técnico-administrativos).

Gráfico 2 - Quantidade de livros de literatura lidos no ano de 2012

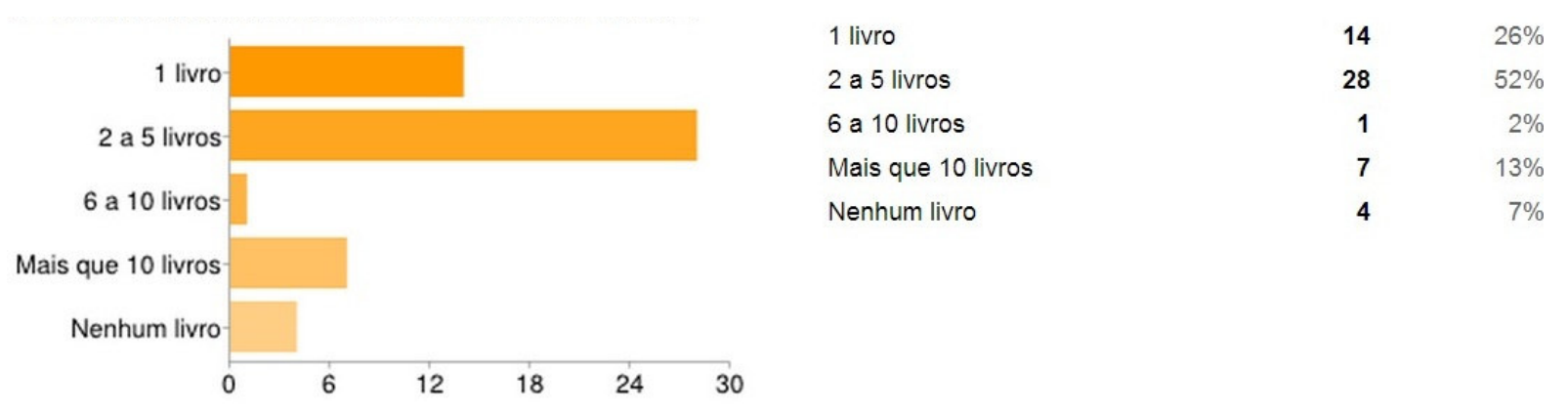

A segunda questão apresenta uma informação relevante no cenário literário, 52\% dos participantes afirmou ler de 2 a 5 livros de literatura por ano, esta informação corrobora a importância da biblioteca investir frequentemente na aquisição de obras literárias e na realização de diversas atividades que promovam o hábito da leitura não obrigatória e divulguem as obras literárias do acervo.

5 O curso técnico de nível médio concomitante ou subsequente é oferecido a quem já concluiu o ensino fundamental e tenha concluído ou esteja cursando no mínimo o segundo ano do ensino médio. Informações extraídas do site oficial do IFSP. Disponível em:< http://www.ifsp.edu.br/index.php/tecnico-concomitante-ousubsequente.html>. Acesso em: 01 fev. 2013. 
Gráfico 3 - Possui conhecimento que a biblioteca possui livros de literatura

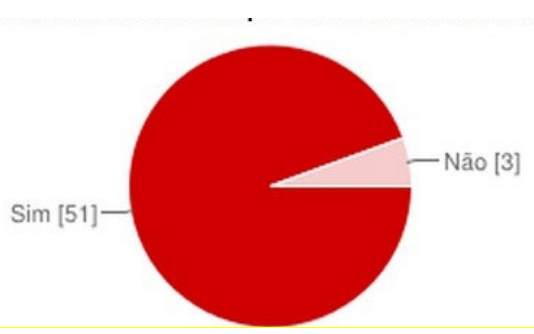

$$
\sin \cdot 51
$$

Não

3

A terceira questão demonstra que a atividade de "Indicação de Leitura" é uma forma de divulgar o acervo literário da biblioteca e convidar os usuários para leituras indicadas.

Gráfico 4 - Frequência de empréstimo dos livros de literatura

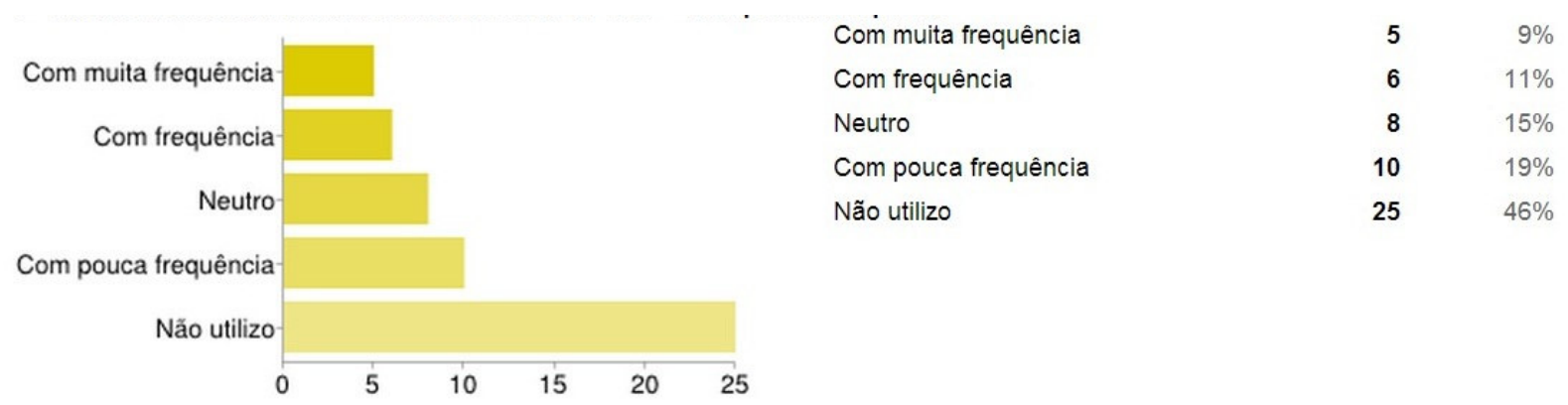

Valor obtida através da escala de Likert: 2,96.

Apesar da maioria dos entrevistados afirmarem ler de 2 a 5 livros por ano compreendeu-se que os livros lidos em sua maioria não são os livros do acervo da biblioteca do IFSP Campus Araraquara, o acervo literário da biblioteca ainda é pequeno, desta forma, se faz necessária uma investigação sobre os "gostos literários" destes usuários, para que sejam adquiridas obras que instiguem a leitura. Ressalta-se que maioria do acervo literário existente é doação, assim, pretende-se trabalhar no levantamento de indicações de livros literários para adiquiridos através de compra pela biblioteca.

Gráfico 5 - Avaliação sobre a biblioteca possuir livros de literatura

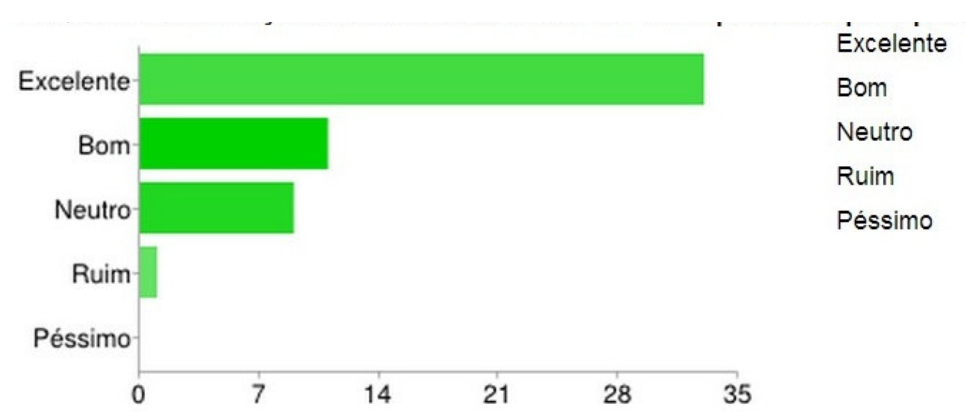

Valor obtida através da escala de Likert: 8,52. 
A maioria dos entrevistados considera excelente a existência de obras literárias no acervo da biblioteca, este é fator motivador para que aquisições literárias sejam feitas, levando em consideração as indicações de obras que poderão ser realizadas pelos próprios usuários. Com base nestas informações a biblioteca do IFSP Campus Araraquara disponibilizará em seu site oficial um formulário para que seus usuários indiquem títulos literários a serem adquiridos, desta forma, as necessidades informacionais dos usuários serão consideradas para estas aquisições.

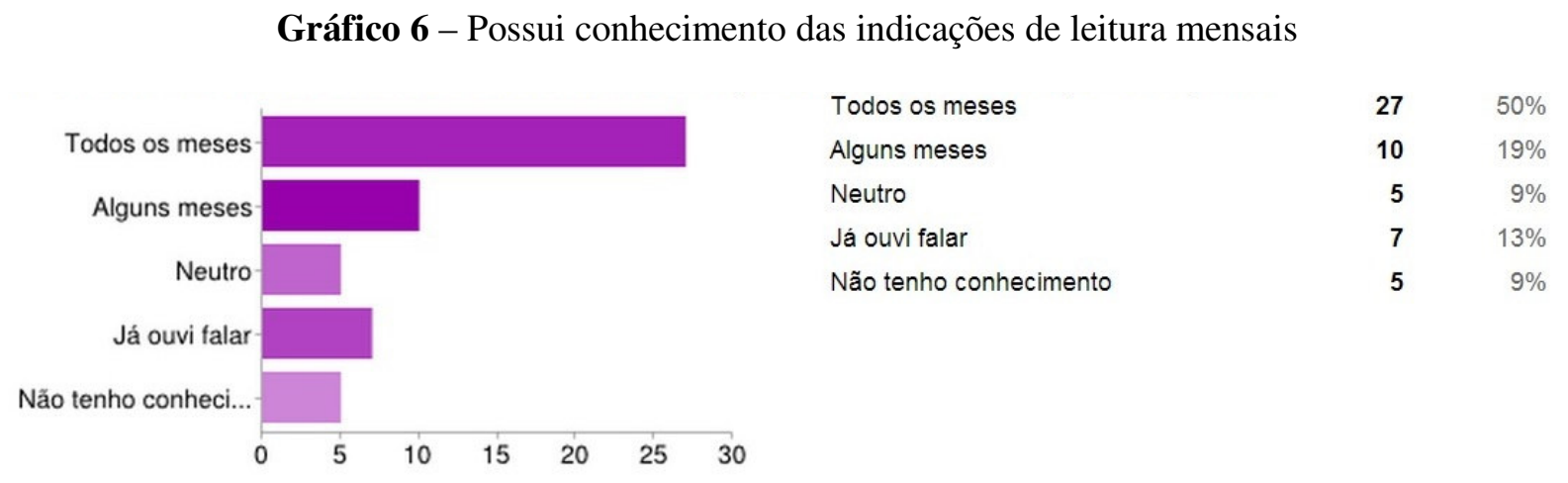

Valor obtida através da escala de Likert: 7,18.

Com a sexta questão ratifica-se que a atividade de "Indicação de Leitura" consegue divulgar o acervo literário da biblioteca, ainda que a maior parte dos livros lidos não são livros pertencentes ao acervo, é salutar o desenvolvimento desta atividade, assim como a aquisição direcionada de livros literários, tendo em vista que a maioria dos entrevistados leem livros de literatura.

Gráfico 7 - Já se interessou em ler livros da indicação de leitura

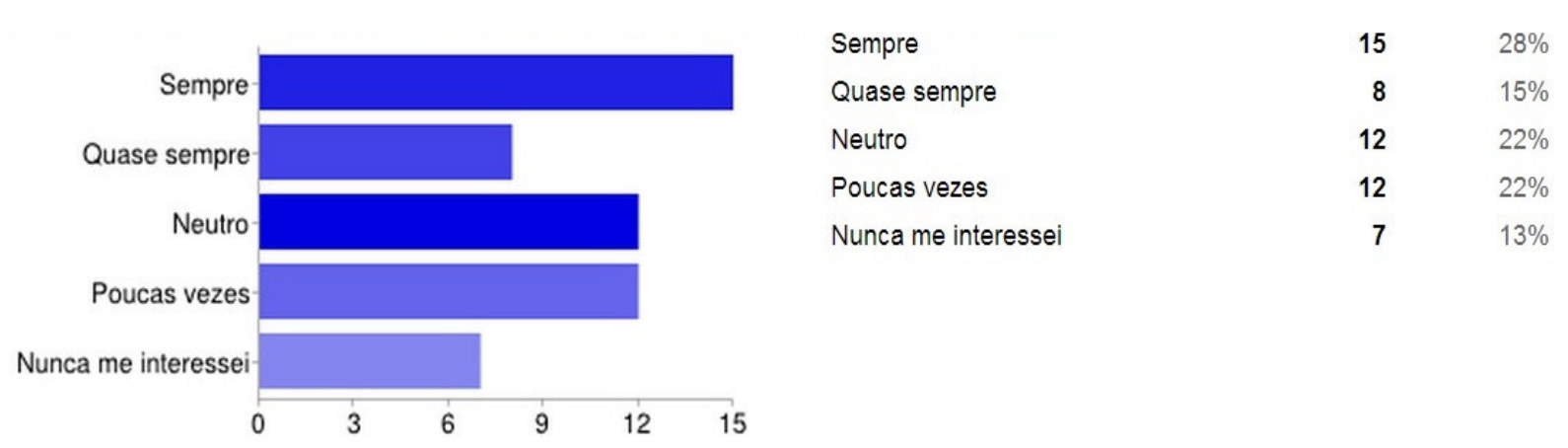

Valor obtida através da escala de Likert: 5,55.

Com a sétima questão compreende-se que a atividade de "Indicação de Leitura" é importante para a divulgação do acervo literário da biblioteca do IFSP Campus Araraquara, porém, nem sempre há o interesse dos usuários em ler as obras indicadas, ainda que conforme 
pesquisas realizadas no Personal Home Library (PHL); software utilizado para o gerenciamento do acervo da biblioteca, as obras indicadas para leitura apresentam quantidade maior de empréstimos, desta forma, se faz necessário o aumento e diversificação do acervo literário da biblioteca.

\section{Conclusões}

Diante do exposto podem-se observar alguns pontos, destaca-se o primeiro ponto que refere-se a surpresa dos usuários num primeiro momento em terem o conhecimento de que a biblioteca do IFSP Campus Araraquara possui livros de literatura em seu acervo, pois aos olhos destes usuários a biblioteca do IFSP Campus Araraquara serviria apenas como suporte meramente técnico ao desenvolvimento dos cursos oferecidos pelo campus, ou seja, os usuários da própria comunidade não possuíam a percepção de que a biblioteca possui uma atuação ampla no campus, a biblioteca e o bibliotecário podem e devem estar inseridos nas variadas facetas do campus: ensino, pesquisa e extensão, à medida que o acervo literário é apresentado e conhecido por estes usuários, os mesmos encaram como positivo e necessário a existência, manutenção e atualização do acervo literário na biblioteca do campus.

O segundo ponto a receber destaque é com relação à interação dos usuários com a biblioteca através da promoção da atividade de "Indicação de Leitura", pois muitos usuários não utilizavam os serviços da biblioteca, por não saberem que no acervo também existiam livros de literatura, assim, a atividade de "Indicação de Leitura" despertou o interesse de alguns leitores em lerem os livros de literatura que ainda não tinham sido indicados, para que a indicação fosse feita, ressalta-se novamente, que o acervo literário precisa aumentar e se diversificar para atingir uma população maior de usuários.

O terceiro ponto de destaque refere-se à importância do desenvolvimento contínuo de atividades de promoção de incentivo à leitura, artísticas e culturais são de extrema importância em um ambiente escolar, assim a biblioteca poderá ser um organismo fomentador de diversas atividades, tais como saraus, varais literários, lançamentos de livros, exposições de arte, dentre outras atividades.

Os autores findam estas sumárias considerações com a sensação de estar "no meio do caminho" no que tange a importância de realizarem práticas de incentivo à leitura, para eles o estar "no meio do caminho", reflete o sentimento de não poder parar de realizar esta atividade 
e muito menos retornar, então o que lhes resta e ainda bem que eles possuem esta opção é continuar persistindo, continuar insistindo para que mais atividades que promovam o incentivo à leitura sejam realizadas, para que mais usuários conheçam o acervo de suas bibliotecas, para que mais usuários leiam os livros disponíveis no acervo das bibliotecas, para que mais usuários dialoguem com vários autores e para que mais bibliotecários e cidadãos sensíveis com a importância da leitura continuem caminhando rumo a novos horizontes, pois assim como poetizou Cora Coralina ${ }^{6}$ "o que vale na vida não é o ponto de partida e sim a caminhada. Caminhando e semeando, no fim terás o que colher”. Assim espera-se que mais livros literários sejam lidos na biblioteca do IFSP Campus Araraquara.

\section{Referências}

BERTAGLIA, S. B.; TREVIZAN, A. Leitura literária: negligenciada, mas indispensável à constituição de um sujeito sensível, crítico, reflexível e transformador. Leitura Crítica. n. 15, jul./ago. 2012. Disponível em: < http://www.leituracritica.com.br/rev12/julga/julga15.htm>. Acesso em: 06 jan. 2013.

BRANDALISE, L. T. et al. A percepção e o comportamento ambiental dos universitários em relação ao grau de educação ambiental. Gest. Prod., São Carlos, v. 16, n. 2, p.273-285, abr./jun. 2009. Disponível em: < http://www.scielo.br/pdf/gp/v16n2/v16n2a10.pdf>. Acesso em: 20 jan. 2013.

BURKE, P. Uma história social do conhecimento: de Gutenberg a Diderot. Rio de Janeiro: Jorge Zahar Editor, 2003. 241 p.

BRASIL. Presidência da República. Lei n 11.892, de 29 de dezembro de 2008. Institui a Rede Federal de Educação Profissional, Científica e Tecnológica, cria os Institutos Federais de Educação, Ciência e Tecnologia. Brasília, DF, 29 dez. 2008. Disponível em: $<$ http://www.planalto.gov.br/ccivil_03/_ato2007-2010/2008/lei/111892.htm>. Acesso em: 04 jan. 2013.

COPOLLA JÚNIOR; C.; CASTRO FILHO, C. M. Biblioteca escolar e a Lei 12.244/2010: caminhos para a implantação. Bibl. Esc. em R., Ribeirão Preto, v. 1, n. 1, p. 30-41, 2012. Disponível em: < http://revistas.ffclrp.usp.br/BEREV/article/view/102/82>. Acesso em: 06 jan. 2013.

\footnotetext{
${ }^{6}$ Cora Coralina pseudônimo de Ana Lins dos Guimarães Peixoto Bretas nasceu em 20 de agosto de 1889 e faleceu em 10 de abril de 1985. Descrita como a grande poetiza do Estado de Goiás, e viveu por muito tempo produzindo de doces, até ficar conhecida como Cora Coralina, ela foi à primeira mulher a ganhar o Prêmio Juca Pato, em 1983, com o livro Vintém de Cobre - Meias Confissões de Aninha. Informações disponíveis em:<http://pensador.uol.com.br/autor/cora_coralina/biografia>. Acesso em: 06 jan. 2013.
} 
FAILLA, Z. (Org.). Retratos da leitura no Brasil 3. São Paulo: Instituto Pró-Livro; Imprensa Oficial de São Paulo, 2012. 348p. Disponível em: <http://www.prolivro.org.br/ipl/publier4.0/dados/anexos/4095.pdf>. Acesso em 04 jan. 2012.

FRASSON; A. V.; PRICINOTTO, I. P.; FECCHIO, M. Leitura: um mundo magnífico a ser melhor explorado. Akrópolis: revista de ciências humanas da UNIPAR, Umuarama, v. 12, n. 3, jul./set. 2004. Disponível em:

<http://revistas.unipar.br/akropolis/article/viewFile/397/362>. Acesso em: 06 jan. 2013.

IFSP CAMPUS ARARAQUARA. 2013. Disponível em: <www.ifsp.edu.br/araraquara>. Acesso em: 05 jan. 2013.

IFSP. Institucional. 2013. Disponível em:

<http://www.ifsp.edu.br/index.php/institucional.html>. Acesso em: 04 jan. 2013.

SANTOS, C. A. S. As unidades de informação dos Institutos Federais no apoio ao desenvolvimento da ciência e da tecnologia: um estudo de percepção sociocognitiva com o uso do protocolo verbal em grupo. 248 f. Dissertação (Mestrado em Ciência, Tecnologia e Sociedade) - Centro de Educação e Ciências, Universidade Federal de São Carlos, 2012.

SANTOS, C. A. S.; SANTOS, M. P. S. Bibliotecas púbicas no século XXI e seus usuários: uma releitura da literatura. CRB-8 Digital, São Paulo, v. 5, n. 2, p.10-16, dez. 2012. Disponível em: < http://revista.crb8.org.br/index.php/crb8digital/article/viewFile/89/89>. Acesso em: 04 jan. 2013.

SILVEIRA, F. J. N. Um elogio à sedução, ou a biblioteca como espaço de leitura. Perspectivas em Ciência da Informação, Belo Horizonte, v. 17, n. 4, p. 142-159, out./dez. 2012. Disponível em: <http://portaldeperiodicos.eci.ufmg.br/index.php/pci/article/view/1486>. Acesso em: 04 jan. 2013. 